\title{
TOWARDS STRONGLY HOM-DAMPED MULTI-CELL RF CAVITIES*
}

\author{
R. Rimmer*, H. Wang, G. Wu, JLAB, Newport News, VA, USA \\ D. Li**, LBNL, Berkeley, CA, USA.
}

\begin{abstract}
This paper discusses the prospects for very strong HOM damping in multi-cell RF cavities. There has been much progress in recent years towards "HOM-free" singlecell cavities. Many examples are now operating in high current storage rings around the world. There have also been successes in broad-band damping of multi-cell structures to levels appropriate for linear colliders and low average current applications. We describe the use of modern simulation tools to explore the potential for applying these techniques to multicell structures. Such cavities would be useful for high-current, high-power applications such as high luminosity collider storage rings, damping rings, energy recovered linacs and injector systems. These methods may be applicable in to both room temperature and superconducting cavities.
\end{abstract}

\section{INTRODUCTION}

Strong HOM damping in accelerator RF cavities has become increasingly important. Storage rings for light sources and colliders now routinely operate with strongly HOM damped single-cell cavities. Linear colliders are proposed that rely upon large numbers of multi-cell cavities with moderate HOM damping. Next generation light sources based on energy recovering linacs (ERL's) require a combination of high-gradient multi-cell structures and strong HOM damping. We study some of the factors that influence the ultimate performance of multi-cell structures using numerical simulations.

\section{SIMULATION METHOD}

We used the time domain module in MAFIA with a simulated bunch to excite the cavity either on or off axis [1]. By recording the wake potential behind the bunch and taking a Fourier transform we were able to calculate the broad-band impedance spectrum. We used the waveguide boundary condition to terminate the beam pipes and any damping apertures. We have not attempted to model the small coaxial DESY type couplers with this method.

\section{BROAD-BAND DAMPING METHODS}

The simplest method of HOM damping is to enlarge the beam pipe on one or both sides of the cavity so all harmful HOMs may propagate away, figs. 1a, 1e, [2]. A modification of this is the fluted beam pipe fig. $1 \mathrm{~b}$, used by Cornell [3]. Waveguide dampers in the beam pipe just outside the cavity, fig. 1c, have been used in CEBAF [4].

\footnotetext{
* This manuscript has been authored by SURA, Inc. under Contract No. DE-AC05-84ER-40150 with the U.S. Department of Energy.

** Contract No. DE-AC03-76SF00098
}

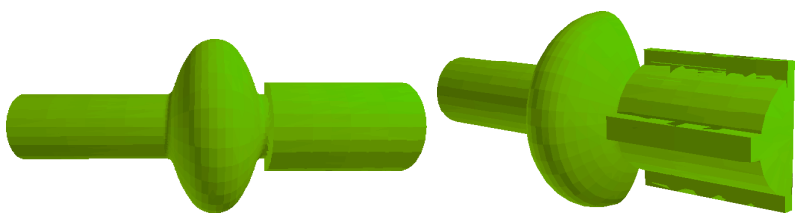

Fig.1a. enlarged beam pipe $1 \mathrm{~b}$. fluted beam pipe

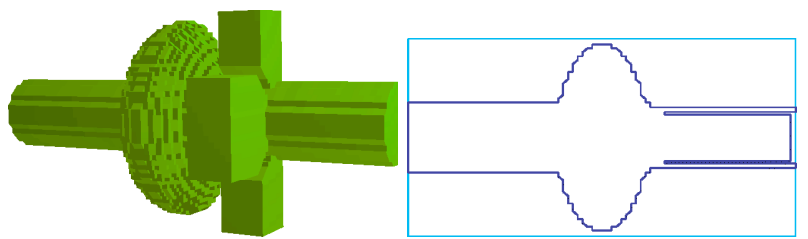

1c. waveguide dampers

1d. coaxial beam pipe
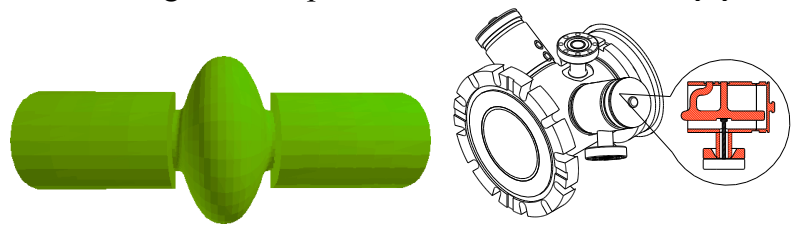

1e. 2 enlarged beam pipes

1f. multiple coaxial loops

A coaxial insert in the beam pipe, fig. 1d, with a choke to reject the fundamental mode, has been proposed for low-order mode damping in deflecting cavities [5]. Coaxial HOM couplers fig. 1f, are already widely used and can give strong coupling if placed appropriately. Normal conducting cavities use openings directly into the accelerating cells for strong HOM damping but this is not normally used for SCRF cavities and is not studied here.

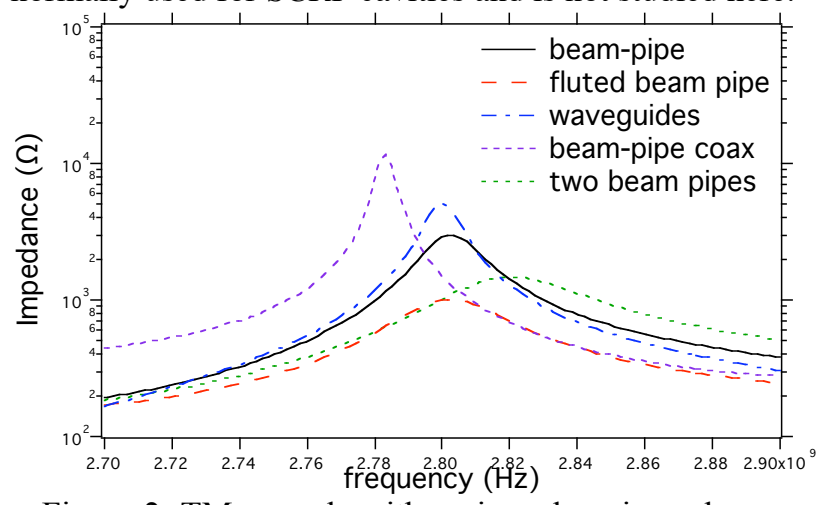

Figure 2. $\mathrm{TM}_{011}$ mode with various damping schemes.

We applied the beam pipe, waveguide and beam-pipecoaxial damping methods to a MAFIA model of a singlecell $1.5 \mathrm{GHz}$ cavity. Figure 2 shows the calculated spectra and table 1 lists the resulting loaded Q's and impedance for the strongest monopole HOM $\left(\mathrm{TM}_{011}\right)$. The beam-pipe damping on one or both sides or with flutes is very effective. The waveguides also give very good damping and the beam-pipe coaxial load is not far behind. Table 2 lists the results for the first two dipole HOMs $\left(\mathrm{TE}_{111}\right.$, $\mathrm{TM}_{110}$ ). Strong damping is also evident in all cases. 
Table 1. $\mathrm{TM}_{011}$ mode for various damping methods

\begin{tabular}{|c|c|c|c|c|}
\hline & freq $\mathrm{MHz}$ & $\mathrm{Q}$ & $\mathrm{R} *(\Omega)$ & $\mathrm{R} / \mathrm{Q}(\Omega)$ \\
\hline b-pipe & 2803 & 252 & 3001 & 11.9 \\
\hline flutes & 2803 & 137 & 1010 & 7.3 \\
\hline wguide & 2800 & 353 & 5040 & 14.3 \\
\hline bp-coax & 2783 & 725 & 11879 & 16.4 \\
\hline 2xbp & 2822 & 121 & 1481 & 12.2 \\
\hline
\end{tabular}

Table 2. Dipole modes for various damping methods

\begin{tabular}{|c|c|c|c|c|c|c|}
\hline & $\begin{array}{c}\mathrm{TE}_{111} \\
\mathrm{f}, \mathrm{MHz}\end{array}$ & $\begin{array}{c}\mathrm{TE}_{111} \\
\mathrm{Q}\end{array}$ & $\begin{array}{c}\mathrm{TE}_{111} \\
\mathrm{R}^{*},(\Omega)\end{array}$ & $\begin{array}{c}\mathrm{TM}_{110} \\
\mathrm{f}, \mathrm{MHz}\end{array}$ & $\begin{array}{c}\mathrm{TM}_{110} \\
\mathrm{Q}\end{array}$ & $\begin{array}{c}\mathrm{TM}_{110} \\
\mathrm{R}^{*}(\Omega)\end{array}$ \\
\hline b-pipe & 1853 & 83 & 246 & 2028 & 130 & 1567 \\
\hline flutes & 1857 & 79 & 239 & 2029 & 130 & 1479 \\
\hline w-guide & 1867 & 553 & 1594 & 2027 & 1131 & 14419 \\
\hline coax & 1924 & 341 & 1496 & 2065 & 502 & 5150 \\
\hline 2xbp & 1830 & 37 & 192 & 2018 & 53 & 735 \\
\hline
\end{tabular}

$* \mathrm{R}$ calculated at $25 \mathrm{~mm}$ offset in the cavity

\section{MULTI-CELL STRUCTURES}

To study the dependence of damping on the number of cells we calculated the monopole and dipole spectra with from one to seven cells per cavity, with open beam pipes on both ends. Figure 3 shows the impedance spectra for the $\mathrm{TM}_{011}$ passband. Tables 3 and 4 list the values for the strongest peak in each passband. Figures 4 and 5 show how the $\mathrm{Q}$ and impedance vary with number of cells. The strength of the highest mode in each passband increases with number of cells slightly faster than linearly. The $\mathrm{TM}_{011}$ and $\mathrm{TE}_{111}$ mode Q's rise with number of cells, the $\mathrm{TM}_{110}$ Q's are higher for even numbers of cells than odd numbers, however the impedance climbs monotonically.

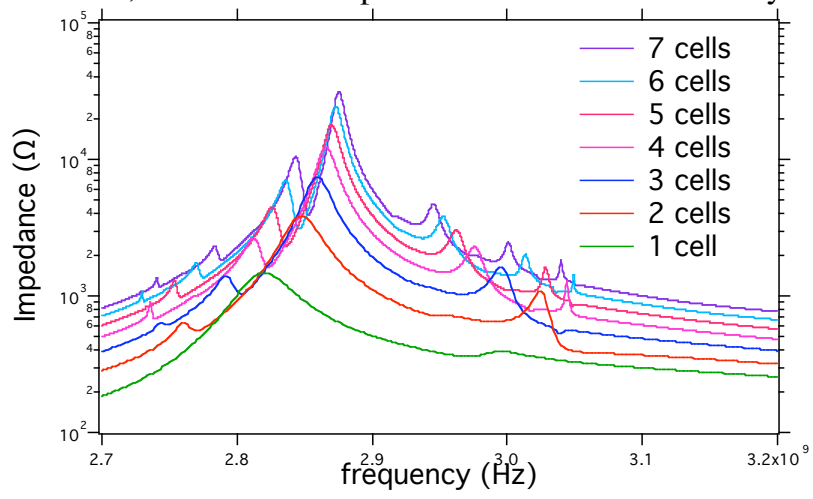

Figure 3. $\mathrm{TM}_{011}$ passband mode vs \# cells

These results suggest that shorter structures might give better overall HOM performance than long ones, however the overhead in length from each HOM load or set of loads may decrease the average "real-estate"gradient. This might be offset by sharing HOM loads and power couplers between adjacent cavities in "superstructure" assemblies [6]. The maximum number of cells at a given frequency may also be influenced by infrastructure constraints, or limits on window or HOM load power.
Table 3. Strongest $\mathrm{TM}_{01}$ passband mode vs \# cells

\begin{tabular}{|c|c|c|c|c|}
\hline \#cells & freq MHz & $\mathrm{Q}$ & $\mathrm{R}^{*}(\Omega)$ & $\mathrm{R} / \mathrm{Q}(\Omega)$ \\
\hline 1 & 2822 & 121 & 1481 & 12.2 \\
\hline 2 & 2848 & 167 & 3856 & 23.0 \\
\hline 3 & 2860 & 219 & 7369 & 33.7 \\
\hline 4 & 2866 & 295 & 12140 & 41.1 \\
\hline 5 & 2870 & 362 & 17795 & 49.1 \\
\hline 6 & 2873 & 455 & 24360 & 53.5 \\
\hline 7 & 2876 & 527 & 31463 & 59.7 \\
\hline
\end{tabular}

Table 4. Strongest $\mathrm{TE}_{111} / \mathrm{TM}_{110}$ passband modes vs \# cells

\begin{tabular}{|c|c|c|c|c|c|c|}
\hline \#cells & $\begin{array}{c}\mathrm{TE}_{111} \\
\mathrm{f}, \mathrm{MHz}\end{array}$ & $\begin{array}{c}\mathrm{TE}_{111} \\
\mathrm{Q}\end{array}$ & $\begin{array}{c}\mathrm{TE}_{111} \\
\mathrm{R}^{*},(\Omega)\end{array}$ & $\begin{array}{c}\mathrm{TM}_{110} \\
\mathrm{f}, \mathrm{MHz}\end{array}$ & $\begin{array}{c}\mathrm{TM}_{110} \\
\mathrm{Q}\end{array}$ & $\begin{array}{c}\mathrm{TM}_{110} \\
\mathrm{R}^{*}(\Omega)\end{array}$ \\
\hline 1 & 1830 & 37 & 192 & 2018 & 53 & 735 \\
\hline 2 & 1907 & 46 & 569 & 2101 & 2641 & 10103 \\
\hline 3 & 1940 & 45 & 1193 & 2093 & 2023 & 14362 \\
\hline 4 & 1867 & 94 & 1844 & 2101 & 4058 & 29270 \\
\hline 5 & 1892 & 121 & 3232 & 2097 & 3233 & 40923 \\
\hline 6 & 1910 & 139 & 4859 & 2102 & 5029 & 46740 \\
\hline 7 & 1922 & 135 & 6088 & 2099 & 4177 & 72101 \\
\hline
\end{tabular}

$* \mathrm{R}$ calculated at $25 \mathrm{~mm}$ offset in the cavity

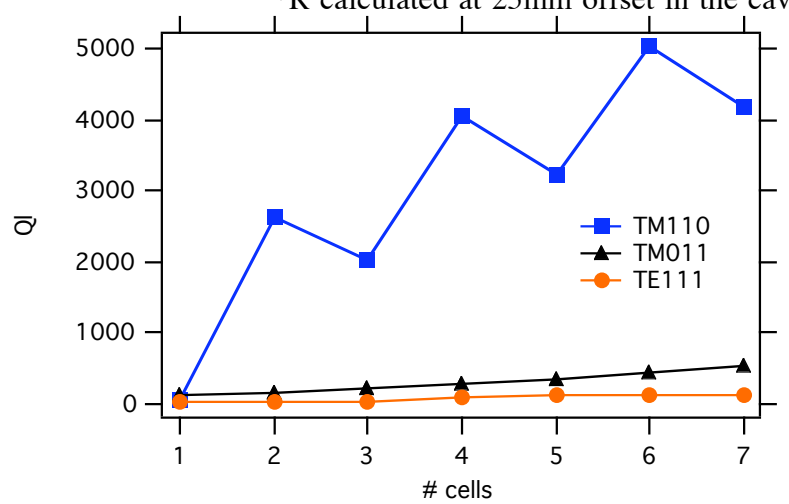

Figure 4. Loaded Q vs \# cells, beam-pipe damping.

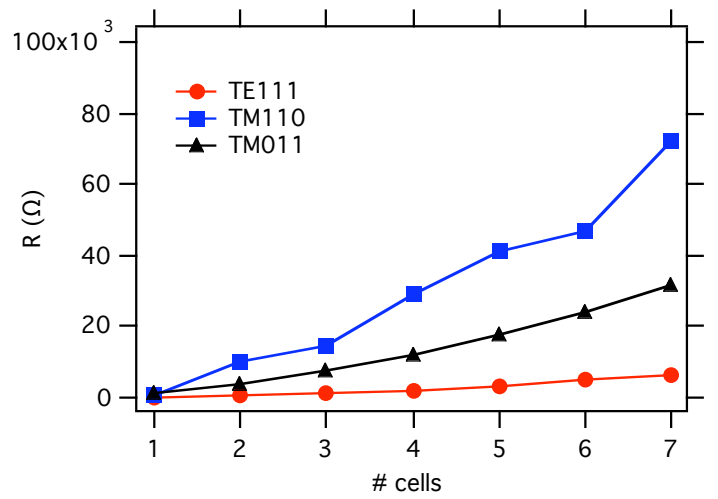

Figure 5. $\mathrm{R}$ vs \# cells ( $\mathrm{R}$ at $25 \mathrm{~mm}$ for dipole modes).

To study the effect of cell shape and coupling strength we compared seven-cell cavities with the original Cornell (OC), high gradient (HG) and low loss (LL) cell shapes [7]. Figure 6 shows the monopole spectrum, while tables 6 and 7 list the peak values for the three passbands. The 
$\mathrm{TM}_{011}$ mode response is similar for the $\mathrm{OC}$ and $\mathrm{HG}$ shapes, while the LL peak is lower in frequency but similar in amplitude (within about a factor of three). The dipole passbands show three distinct spectra and about a factor of two spread in amplitude for the $\mathrm{TE}_{111}$ mode and about a factor of four in the $\mathrm{TM}_{110}$ mode. There does not appear to be any correlation between HOM strength and cell-to-cell coupling in these results. In an operating accelerator the exact mode spectrum could make orders of magnitude difference in BBU threshold and HOM power, so cell profile may be important in this regard.

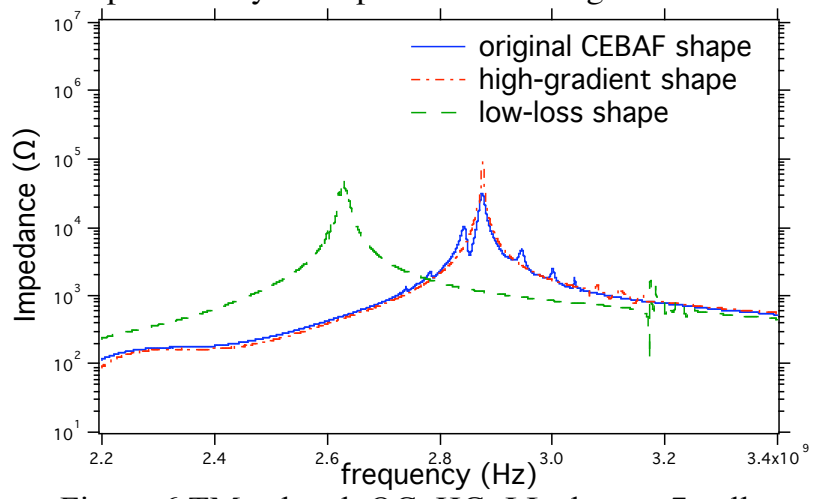

Figure 6.TM $\mathrm{TM}_{011}$ band, OC, HG, LL shapes, 7-cells.

Table 5. $\mathrm{TM}_{011}$ mode data for multi-cell cavities.

\begin{tabular}{|c|c|c|c|c|c|}
\hline & \#cells & Freq,MHz & $\mathrm{Q}$ & $\mathrm{R}^{\dagger}(\Omega)$ & $\mathrm{R} / \mathrm{Q}(\Omega)$ \\
\hline OC & 7 & 2876 & 527 & 31463 & 59.7 \\
\hline HG & 7 & 2876 & 1348 & 90380 & 67.0 \\
\hline LL & 7 & 2629 & 985 & 53556 & 54.4 \\
\hline OC $^{*}$ & 5 & 2871 & 707 & 35453 & 50.1 \\
\hline DESY*** & 4 & 910 & 600 & & \\
\hline
\end{tabular}

*waveguide damped. $* * 500 \mathrm{MHz}$ cavity, meas. $\mathrm{Q} .{ }^{\dagger} \mathrm{R}=\mathrm{V}^{2} / 2 \mathrm{P}$

Table 6. $\mathrm{TE}_{111} / \mathrm{TM}_{110}$ mode data for multi-cell cavities.

\begin{tabular}{|c|c|c|c|c|c|c|c|}
\hline & $\begin{array}{c}\# \\
\text { cells }\end{array}$ & $\begin{array}{c}\mathrm{TE}_{111} \\
\mathrm{f}, \mathrm{MHz}\end{array}$ & $\begin{array}{c}\mathrm{TE}_{111} \\
\mathrm{Q}\end{array}$ & $\begin{array}{c}\mathrm{TE}_{111} \\
\mathrm{R}^{\dagger},(\Omega)\end{array}$ & $\begin{array}{c}\mathrm{TM}_{110} \\
\mathrm{f}, \mathrm{MHz}\end{array}$ & $\begin{array}{c}\mathrm{TM}_{110} \\
\mathrm{Q}\end{array}$ & $\begin{array}{c}\mathrm{TM}_{110} \\
\mathrm{R}^{\dagger}(\Omega)\end{array}$ \\
\hline OC & 7 & 1922 & 135 & 6088 & 2099 & 4177 & 72101 \\
\hline HG & 7 & 2014 & 185 & 11359 & 2156 & 5694 & 146409 \\
\hline LL & 7 & 2021 & 490 & 14107 & 2209 & 2071 & 39510 \\
\hline OC* & 5 & 1894 & 956 & 22949 & 2103 & 3274 & 47064 \\
\hline DESY & 4 & 650 & 4000 & & 716 & 6000 & \\
\hline
\end{tabular}

*waveguide damped. ${ }^{\dagger} \mathrm{R}$ calculated at $25 \mathrm{~mm}$ offset in cavity.

\section{EXAMPLES}

Figure 7 shows a five cell structure with waveguide damping. The highest peaks in each passband are listed in tables $5 \& 6$ (row 4). The $\mathrm{TM}_{011}$ peak is about a factor of two stronger for the waveguide damped cavity than for the beam pipe loaded one (table 3 row 5). For the $\mathrm{TE}_{111}$ mode (table 4 row 5), the factor is about eight but for the strongest dipole $\left(\mathrm{TM}_{110}\right)$ mode they are about the same The waveguide dampers take up very little beam line space compared to the beam pipe loads and can transport HOM power to room temperature loads if required.
Included in tables $5 \& 6$ are data for a four-cell 500 $\mathrm{MHz}$ DESY cavity damped by three coaxial HOM couplers [8]. The $\mathrm{TM}_{011} \mathrm{Q}$ is very similar to the waveguide loaded cavity while the $\mathrm{TE}_{111} \mathrm{Q}$ is a factor of four higher and the $\mathrm{TM}_{110}$ is only up about a factor of two. All of these examples are in the range suitable for next generation high current ERL's

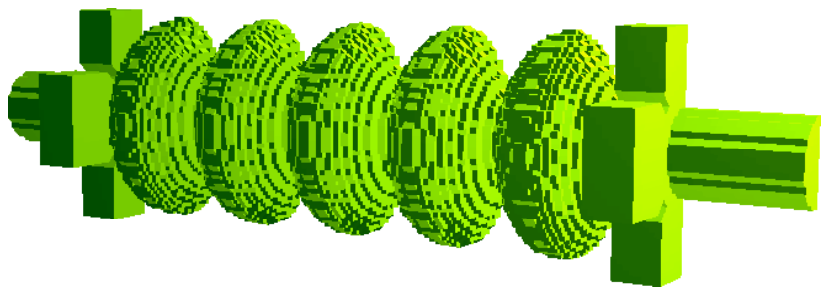

Figure 7. Waveguide damped 5-cell structure.

Other factors such as distortion due to tuning and field tilt might contribute to higher Q's. Having dampers at both ends of the cavity should help. Having symmetrically arranged couplers so that no transverse kick is imparted to the passing beam is also desirable.

\section{CONCLUSIONS}

We have shown that strong broad-band HOM coupling techniques used on single-cell cavities can plausibly be applied to multi-cell cavities. None of the schemes described here have been optimized but all show promise. The ultimate limit may be the rate at which energy can propagate through the cavity. To go significantly further we may want to look at more open structures. We would like to thank Jacek Sekutowicz for useful discussions on this topic.

\section{REFERENCES}

[1] "Beam Impedance Calculation and Analysis of Higher Order Modes (HOMS) Damped RF Cavities Using MAFIA in Time Domain", Derun Li , Robert A. Rimmer, Proc. PAC 2001, Chicago.

[2] "A Prototype Module of Superconducting Damped Cavity for KEKB" T. Furuya et. al., Proc. EPAC96, Barcelona, Spain.

[3] S. Belomestnykh et. al. "Commissioning of the Superconducting RF Cavities for the CESR Luminosity Upgrade", Proc. PAC99, New York.

[4] J.C. Amato, Proc. third Workshop on RF Superconductivity, Argonne, IL, USA. ANL-PHY88-1, Vol.1., p 589, 1988.

[5] K. Hosoyama et al., "Crab Cavity for KEKB", Proc. 7th Workshop on RF Superconductivity (1995).

[6] "Superstructures for High Current FEL Application". J. Sekutowicz et.al., these proceedings

[7] "Cavities for JLAB's $12 \mathrm{GeV}$ Upgrade"J. Sekutowicz et.al., these proceedings

[8] "Superconducting Cavities for HERA", B. Dwersteg et.al., Proc. $3^{\text {rd }}$ Workshop on RF Superconductivity, Argonne, IL, USA. ANL-PHY-88-1, Vol.1., 1988. 